J. Lake Sci.(湖泊科学), 2016, 28(2): 395-404

DOI 10. $18307 / 2016.0220$

(c) 2016 by Journal of Lake Sciences

\title{
洞庭湖大型底栖动物群落结构和水质评价”
}

\author{
王丑明, 张屹, 石慧华, 李利强林, 黄代中, 田琪, 陈 翔, 龚 正, 李 虹 \\ (湖南省洞庭湖生态环境监测中心, 岳阳 414000)
}

\begin{abstract}
摘 要: 2014 年 4 个季度对洞庭湖大型底栖动物进行调查, 共记录底栖动物 4 门 7 纲 58 种, 其中塞毛类 7 种, 软体动物 28 种, 水生昆虫 19 种, 线虫 1 种, 蛭类 2 种, 钩虾 1 种. 洞庭湖底栖动物平均密度为 $187.4 \mathrm{ind} . / \mathrm{m}^{2}$, 软体动物是最主要的 类群, 平均密度为 $88.7 \mathrm{ind} . / \mathrm{m}^{2}$, 占总密度的 $47.3 \%$, 塞毛类和水生昆虫的密度分别为 24.1 和 $27.8 \mathrm{ind} . / \mathrm{m}^{2}$, 分别占总密 度的 12.9\%和 14.9\% . 河蚬 (Corbicula fluminea)、铜锈环棱螺(Bellamya aeruginosa)、苏氏尾鰓蚂(Branchiura sowerbyi)、指 突隐摇蚊 (Cryptochironomus digitatus) 和钩虾 (Gammaridae sp.) 为洞庭湖的优势种. 典范对应分析表明, 水温和溶解氧是 影响洞庭湖底栖动物分布的关键环境因子. 采用 Shannon-Wiener 多样性指数和 $B I$ 生物指数对洞庭湖各样点的水质状况 进行评价, 总体上评价结果分别为轻污染和良好, 结果表明二者具有一定的差异, 结合洞庭湖各样点的综合营养状态指 数可以看出, $B I$ 指数的评价更加适合洞庭湖水质评价.
\end{abstract}

关键词: 洞庭湖; 大型底栖动物; 群落结构;水质评价

\section{Macrozoobenthic community structure and bioassessment of water quality in Lake Dongting, China}

WANG Chouming, ZHANG Yi, SHI Huihua, LI Liqiang ${ }^{* * *}$, HUANG Daizhong, TIAN Qi, CHEN Xiang, GONG Zheng \& LI Hong

( Lake Dongting Eco-Environment Monitoring Centre, Yueyang 414000, P.R.China)

Abstract: Macrozoobenthos were quarterly investigated in Lake Dongting in 2014, a total of 58 species belonging to 4 Phylums and 7 Classes were recorded, including 7 Oligochaeta, 28 Mollusca, 19 Insecta, 1 Nematoda, 2 Hirudinea and 1 Gammaridae. The average density of macrozoobenthos was 187.4 ind. $/ \mathrm{m}^{2}$, of which mainly represented by mollusks. The density of mollusks, oligochaetes and aquatic insects was $88.7,24.1$ and 27.8 ind. $/ \mathrm{m}^{2}$, accounted for $47.3 \%, 12.9 \%$ and $14.9 \%$ of total density, respectively. The dominant species were Corbicula fluminea, Bellamya aeruginosa, Branchiura sowerbyi, Cryptochironomus digitatus and Gammaridae sp.. Canonical correspondence analysis showed water temperature and dissolved oxygen were highly correlated with macrozoobenthic community structure. Shannon-Wiener diversity index and Hilsenhoff's Biotic Index (BI) were calculated to assess the water quality of Lake Dongting, the evaluation result was light pollution and good respectively. The results of two indices were different to a certain extent, combined with $\sum T L I, B I$ methods was more suitable for bioassessment in Lake Dongting.

Keywords: Lake Dongting; macrozoobenthos; community structure; water quality bioassessment

洞庭湖 $\left(28^{\circ} 44^{\prime} \sim 29^{\circ} 25^{\prime} \mathrm{N}, 111^{\circ} 53^{\prime} \sim 113^{\circ} 5^{\prime} \mathrm{E}\right.$ ) 为湖南省第一大湖, 全国第二大淡水湖, 是承纳湘、资、沅、 澧“四水”和吞吐长江的过水性洪道型湖泊,有调节气候、涵养水源、净化水质、维护生物多样性和改善生态 环境等多种功能. 洞庭湖天然湖泊面积 $2691 \mathrm{~km}^{2}$, 另有内湖面积 $1200 \mathrm{~km}^{2}$, 洪道面积 $1013 \mathrm{~km}^{2}$, 流域涉及 湘、鄂、黔、渝、桂、粤六省,湖体形状呈近似“U”字形,岳阳站水位 $33.5 \mathrm{~m}$ (黄海基面) 时湖长 $143 \mathrm{~km}$,最大湖 宽 $30 \mathrm{~km}$, 平均湖宽 $17 \mathrm{~km}$, 最大水深 $23.5 \mathrm{~m}$, 平均水深 $6.4 \mathrm{~m}$, 相应蓄水量 $167 \times 10^{8} \mathrm{~m}^{3}$, 三峡建设之前, 洞庭 湖水循环周期约 $18.2 \mathrm{~d}^{[1]}$. 洞庭湖流域采砂较为严重,因此底质泥沙淤积较多,有机质含量较低,但重金属 含量较高。洞庭湖湿地植被以禾本科、菊科、莎草科、蓼科、豆科和唇形科以及杨柳科等为主, 芦苇

* 2015-02-10 收稿;2015-07-13 收修改稿. 王丑明(1984 ), 男,硕士;E-mail: wangchouming@ 126.com.

** 通信作者;E-mail: liliqiang858@163.com. 
(Phragmites australis) 和南荻 (Triarrhena lutarioriparia) 是湖岸带优势挺水植物, 黑藻 (Hydrilla verticillata) 和 金鱼藻 (Ceratophyllum demersum) 是洞庭湖优势沉水植物.

近几十年来, 随着湖区经济快速发展和人口急剧增长, 人类对其自然资源的开发不断加剧, 使其生态环 境逐渐恶化, 富营养化进程日益加剧, 东洞庭湖已经呈现轻度富营养化状态, 并影响到底栖动物群落结构和 多样性 ${ }^{[2]}$. 洞庭湖水体主要污染物为氮和磷 ${ }^{[3]}$, 一般而言, 底栖动物种类、多样性与水体总氮、总磷等营养盐 浓度呈负相关 ${ }^{[4-6]}$. 底栖动物是水域生态系统中的重要组成部分, 在水域生态系统中起着重要作用, 在水体 净化方面, 底栖动物能摄食沉积物, 加速腐质的分解, 使腐质得到再循环, 促进水体自净 ${ }^{[7]}$; 在渔业方面, 大 型底栖动物对鱼类有明显的上行效应 ${ }^{[8]}$, 食物网的同位素研究也证明了能量从藻类一大型无脊椎动物一鱼 类的传递过程 ${ }^{[9]}$; 在水质生物评价方面, 由于其具有种类多、生活周期较长、活动场所比较固定、易于采集, 且不同种类对水质的敏感性差异大、受外界干扰后群落结构的变化趋势经常可以预测等一系列优点, 因此 一直是了解水生生态系统结构功能及健康状况的关键类群 ${ }^{[10]}$; 在生物多样性方面, 淡水生物类群的灭绝速 率是陆地生物类群的 5 倍或更多 ${ }^{[11]}$, 有些底栖动物种群数量本身就较低, 它们灭绝了可能还不为人类所知, 因此对特定区域的底栖动物进行生物多样性调查很有意义. 然而目前洞庭湖底栖动物方面的研究较 少 ${ }^{[12-18]}$, 戴友芝等 ${ }^{[12]}$ 在 1995 年对洞庭湖底栖动物进行调查并对水质进行评价, 发现洞庭湖为轻污染, 汪星 等 ${ }^{[13]}$ 在 2010 年对洞庭湖底栖动物进行调查, 发现底栖动物组成以软体动物占优势, 虽有少量对某一湖 区 $^{[15-16]}$ 或某一类群的研究 ${ }^{[17-18]}$, 但这些不足以全面体现洞庭湖底栖动物特征. 本文根据湖南省洞庭湖生态 环境监测中心在 2014 年 3、6、9、12 月对洞庭湖全湖底栖动物的调查研究结果, 结合水体理化指标, 应用典范 对应分析方法分析影响洞庭湖大型底栖动物的主要环境因子, 并评价洞庭湖水质状况, 期望为治理和保护 洞庭湖提供科学数据.

\section{1 材料与方法}

\section{1 采样点布设与样品采集}

在洞庭湖共设有 15 个监测断面, 具体如下: 西洞庭湖湖区的蒋家嘴 $\left(5^{*}\right)$ 、南嘴 $\left(6^{\#}\right)$ 和小河嘴 $\left(7^{\#}\right)$ 断 面; 东洞庭湖湖区的鹿角 $\left(11^{\#}\right)$ 、东洞庭湖 $\left(12^{\#}\right)$ 、岳阳楼 $\left(13^{\#}\right)$ 、大小西湖 $\left(15^{\#}\right)$; 南洞庭湖湖区的万子湖 $\left(8^{\#}\right)$ 、虞公庙 $\left(9^{\#}\right)$ 和横岭湖 $\left(10^{\#}\right)$ 断面; 人湖口的樟树港 $\left(1^{\#}\right)$ 、万家嘴 $\left(2^{\#}\right)$ 、坡头 $\left(3^{\#}\right)$ 和沙河口 $\left(4^{\#}\right)$ 断面以 及洞庭湖出口 $\left(14^{\#}\right)$ 断面 (图 1), 采样时间为 2014 年 3、6、9、12 月. 底栖动物的采集使用 $0.0625 \mathrm{~m}^{2}$ 的改良 彼得森采泥器, 每断面采左、右点, 每点用采泥器连续取 2 次泥样混合后经 40 目分样篮筛洗, 按常规方法挑 拣出生物标本, 然后分别装袋. 寡毛类用 $4 \% \sim 10 \%$ 的福尔马林溶液固定, 软体类、水生昆虫等用 $75 \%$ 的酒精 保存, 回实验室鉴定计数, 每个断面的底栖动物数量均取其左、右采样点的平均值. 标本的鉴定参考文献 [19-22].

测定水温 $(\mathrm{WT})$ 、电导率 $(\mathrm{COND}) 、 \mathrm{pH}$ 值、溶解氧 $(\mathrm{DO})$ 、透明度 $(\mathrm{SD})$ 、总磷 $(\mathrm{TP})$ 、总氮 $(\mathrm{TN})$ 、氨氮 $\left(\mathrm{NH}_{3}-\mathrm{N}\right)$ 、 化学需氧量 $\left(\mathrm{COD}_{\mathrm{Cr}}\right)$ 、五日生化需氧量 $\left(\mathrm{BOD}_{5}\right)$ 、高锰酸盐指数 $\left(\mathrm{COD}_{\mathrm{Mn}}\right)$ 、叶绿素 $\mathrm{a}(\mathrm{Chl} . \mathrm{a})$ 共 12 项环境参数, 表层水样中, Chl. a 、 $\mathrm{BOD}_{5} 、 \mathrm{COD}_{\mathrm{Cr}} 、 \mathrm{TN} 、 \mathrm{TP} 、 \mathrm{COD}_{\mathrm{Mn}}$ 以及 $\mathrm{NH}_{3}-\mathrm{N}$ 的测定方法参照《水和废水监测分析方法》(第 4 版 ${ }^{[23]}$, WT、COND、pH 值和 DO 浓度采用 YSI 现场直接测定, SD 采用透明度盘测定.

\section{2 数据处理}

底栖动物物种多样性的计算采用 Shannon-Wiener 指数, 即 $H^{\prime}=-\sum\left\{\left(n_{i} / N\right) \log _{2}\left(n_{i} / N\right)\right\}, B I$ 生物指数计 算方法为: $B I=\sum a_{i}\left(n_{i} / N\right)$, 式中, $n_{i}$ 为第 $i$ 分类单元的个体数; $a_{i}$ 为第 $i$ 分类单元的耐污值; $N$ 为各分类单元的 个体总和. 物种损失率计算公式为: $P=\left(S-S_{i}\right) / S_{i}$, 式中, $S$ 为本次调查的种类数, $S_{i}$ 为 $i$ 年前的种类数. 综 合营养状态指数与底栖动物物种数的相关分析用 SPSS 13.0 软件中的 Pearson 相关. 湖泊营养状态评价指 标为 TN、TP、COD $\mathrm{Mn}_{\mathrm{n}}$, Chl. a 和 $\mathrm{SD}$, 采用《湖泊 (水库) 富营养化评价方法及分级技术规定》中的综合营养状态 指数评价方法进行评价 ${ }^{[24]}$.

采用约束排序 ( constrained ordination) 分析洞庭湖底栖动物群落分布与环境因子之间的关系. 采用 4 个 季度的平均值做典范对应分析 (canonical correspondence analysis, CCA). 环境参数平均后进行自然对数转化 后作为环境数据源; 大型底栖动物群落组成作为生物数据源, 构成环境因子与种类矩阵. 对底栖动物群落 


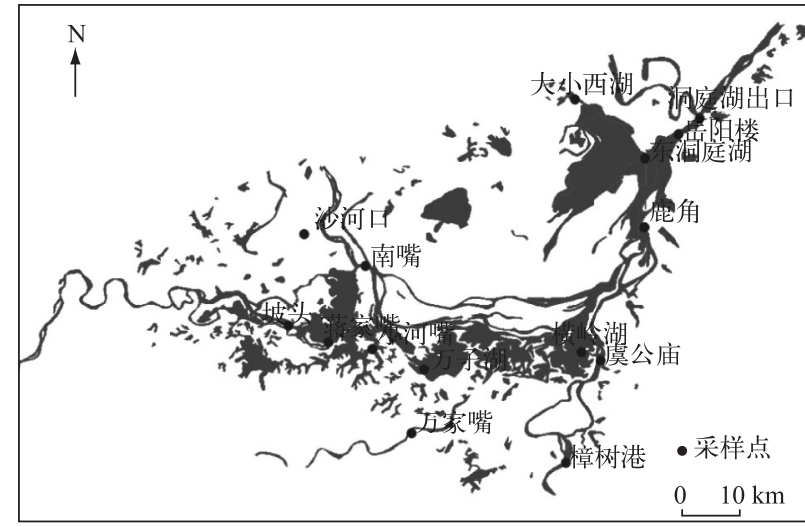

图 1 洞庭湖大型底栖动物采样点分布

Fig. 1 Distribution of sampling sites of macrozoobenthos in Lake Dongting

分布的除趋势对应分析 (detrended correspondence analysis, DCA) 显示非线性模式 (gradient length $>2$ standard units) 更适合功能类群与环境因子关系的分析 ${ }^{[25]}$, 因此采用 CCA 进行分析.

为了优化分析, 底栖动物群落数据进行 $\lg (x+1)$ 转化, 具有较高偏相关关系的环境因子 $(r>0.80)$ 和膨 胀因子 (inflation factor) 大于 20 的环境因子均被剔除 ${ }^{[26]}$, 并在分析中降低了稀有种的权重 (downweighting option). 用前向选择 (forward selection) (显著性水平为 0.05 ) 和蒙特卡罗置换检验 ( 499 permutations) 确定对 底栖动物功能摄食类群分布具有重要并独立作用的最少变量组合. 该最小变量组用于最终的 CCA 分析中. 数据分析采用 Canoco for Windows 4.5 软件.

\section{3 水质的生物学评价}

采用 Shannon-Wiener 指数和 $B I$ 生物指数对洞庭湖的水质进行生物评价. Shannon-Wiener 指数评价标 准: 指数值 $>3$, 优; $2 \sim 3$ 良好; 1 2 轻污染; $0.5 \sim 1$ 中污染; $0 \sim 0.5$ 重污染. $B I$ 水质评价标准为: $B I=0 \sim 5.5$, 优; 5. 5 6. 5, 良好; 6. 5 7.5, 轻污染; 7.5 8.5, 中污染; 8. 5 10, 重污染. 所收集到的底栖动物样本的耐污 值参考文献[27-29].

\section{2 结果}

\section{1 环境因子}

大小西湖的 $\mathrm{pH}$ 值、COD $\mathrm{CO}_{\mathrm{Mn}} 、 \mathrm{COD}_{\mathrm{Cr}} 、 \mathrm{BOD}_{5} 、 \mathrm{TP}$ 和 Chl. a 浓度最高, 分别为 $7.87 、 5.33 \mathrm{mg} / \mathrm{L} 、 20.0 \mathrm{mg} / \mathrm{L}$ 、 $3.20 \mathrm{mg} / \mathrm{L} 、 0.13 \mathrm{mg} / \mathrm{L} 、 12.8 \mathrm{mg} / \mathrm{m}^{3}$; 资江人湖口的万家嘴水温最高, 为 $21.9^{\circ} \mathrm{C}$; 西洞庭湖的蒋家嘴电导率最 高, 为 $301 \mu \mathrm{S} / \mathrm{cm}$; 东洞庭湖的岳阳楼溶解氧和 $\mathrm{NH}_{3}-\mathrm{N}$ 浓度最高, 分别为 8.42 和 $0.35 \mathrm{mg} / \mathrm{L}$; 南洞庭湖的横 岭湖 TN 浓度最高, 为 $2.57 \mathrm{mg} / \mathrm{L}$; 沅江人湖口的坡头透明度最高, 为 $0.61 \mathrm{~m}$. 大小西湖为东洞庭湖国家级自 然保护区的核心区,水流较慢, 营养盐浓度较高, $\mathrm{COD}_{\mathrm{Mn}} 、 \mathrm{COD}_{\mathrm{Cr}} 、 \mathrm{BOD}_{5}$ 和 $\mathrm{Chl}$. a 浓度明显高于其它湖区 (表 $1)$,在 9 月份的调查中发现有蓝藻水华,综合营养状态指数为 58.5 ,为轻度富营养化.

\section{2 底栖动物群落结构}

2014 年 4 个季度对洞庭湖大型底栖动物进行调查, 共记录动物 4 门 7 纲 58 种, 其中寡毛类 7 种, 软体动 物 28 种, 水生昆虫 19 种, 其他动物 4 种 (附表). 洞庭湖底栖动物平均密度为 $187.4 \mathrm{ind} . / \mathrm{m}^{2}$, 软体动物是最 主要的类群, 平均密度为 $88.7 \mathrm{ind} . / \mathrm{m}^{2}$, 占总密度的 $47.3 \%$, 臭毛类和水生昆虫的密度分别为 24.1 和 27.8 ind. $/ \mathrm{m}^{2}$, 分别占总密度的 $12.9 \%$ 和 $14.9 \%$.

以平均相对密度大于 $5 \%$ 计, 洞庭湖底栖动物优势种为双壳类的河蚬、腹足类的铜锈环棱螺、寡毛类的 苏氏尾鳃蚓、摇蚊科的指突隐摇蚊和甲壳类的钩虾. 
表 1 洞庭湖 15 个样点的理化指标

Tab. 1 Physical and chemical characteristics of 15 sampling sites in Lake Dongting

\begin{tabular}{ccccccccccccc}
\hline 样点 & $\begin{array}{c}\mathrm{WT} / \\
{ }^{\circ} \mathrm{C}\end{array}$ & $\mathrm{pH}$ 值 & $\begin{array}{c}\mathrm{SD} / \\
\mathrm{m}\end{array}$ & $\begin{array}{c}\mathrm{COND} / \\
(\mu \mathrm{S} / \mathrm{cm})\end{array}$ & $\begin{array}{c}\mathrm{DO} / \\
(\mathrm{mg} / \mathrm{L})\end{array}$ & $\begin{array}{c}\mathrm{COD}_{\mathrm{Mn}} / \\
(\mathrm{mg} / \mathrm{L})\end{array}$ & $\begin{array}{c}\mathrm{COD}_{\mathrm{Cr}} / \\
(\mathrm{mg} / \mathrm{L})\end{array}$ & $\begin{array}{c}\mathrm{BOD}_{5} / \\
(\mathrm{mg} / \mathrm{L})\end{array}$ & $\begin{array}{c}\mathrm{NH}_{3}-\mathrm{N} / \\
(\mathrm{mg} / \mathrm{L})\end{array}$ & $\begin{array}{c}\mathrm{TN} / \\
(\mathrm{mg} / \mathrm{L})\end{array}$ & $\begin{array}{c}\mathrm{TP} / \\
(\mathrm{mg} / \mathrm{L})\end{array}$ & $\begin{array}{c}\mathrm{Chl} . \mathrm{a} / \\
\left(\mathrm{mg} / \mathrm{m}^{3}\right)\end{array}$ \\
\hline $1^{\#}$ & 20.6 & 7.52 & 0.51 & 261 & 6.12 & 2.60 & 9.76 & 1.84 & 0.32 & 2.54 & 0.09 & 1.77 \\
$2^{\#}$ & 21.9 & 7.65 & 0.38 & 198 & 6.55 & 2.47 & 9.21 & 1.89 & 0.11 & 2.13 & 0.04 & 1.96 \\
$3^{\#}$ & 19.0 & 7.56 & 0.61 & 190 & 6.61 & 2.39 & 8.42 & 2.10 & 0.11 & 1.70 & 0.09 & 1.36 \\
$4^{\#}$ & 18.6 & 7.83 & 0.35 & 290 & 6.74 & 2.58 & 11.98 & 2.12 & 0.23 & 2.06 & 0.10 & 0.87 \\
$5^{\#}$ & 17.0 & 7.82 & 0.34 & 301 & 7.87 & 2.88 & 8.17 & 2.18 & 0.19 & 1.99 & 0.12 & 1.92 \\
$6^{\#}$ & 17.9 & 7.78 & 0.54 & 211 & 6.81 & 2.37 & 6.67 & 1.73 & 0.09 & 1.66 & 0.08 & 1.13 \\
$7^{\#}$ & 17.1 & 7.82 & 0.55 & 216 & 7.71 & 2.58 & 7.56 & 1.96 & 0.10 & 1.70 & 0.09 & 1.50 \\
$8^{\#}$ & 17.3 & 7.83 & 0.45 & 202 & 7.73 & 2.35 & 6.67 & 1.92 & 0.13 & 1.79 & 0.08 & 1.77 \\
$9^{\#}$ & 17.4 & 7.80 & 0.43 & 234 & 7.65 & 2.40 & 6.54 & 1.71 & 0.11 & 1.80 & 0.09 & 1.52 \\
$10^{\#}$ & 17.8 & 7.65 & 0.42 & 249 & 6.85 & 2.51 & 8.25 & 2.04 & 0.24 & 2.57 & 0.08 & 1.55 \\
$11^{\#}$ & 18.0 & 7.68 & 0.34 & 237 & 6.81 & 2.43 & 8.92 & 2.17 & 0.20 & 2.20 & 0.11 & 1.64 \\
$12^{\#}$ & 16.5 & 7.78 & 0.39 & 270 & 8.39 & 2.68 & 9.33 & 2.34 & 0.09 & 1.95 & 0.11 & 3.35 \\
$13^{\#}$ & 16.8 & 7.78 & 0.36 & 271 & 8.42 & 2.39 & 9.17 & 2.39 & 0.35 & 2.16 & 0.09 & 2.20 \\
$14^{\#}$ & 16.8 & 7.83 & 0.46 & 292 & 8.37 & 2.46 & 9.33 & 2.34 & 0.22 & 2.17 & 0.10 & 2.27 \\
$15^{\#}$ & 19.2 & 7.87 & 0.43 & 287 & 6.30 & 5.33 & 20.00 & 3.20 & 0.22 & 2.14 & 0.13 & 12.80 \\
\hline
\end{tabular}

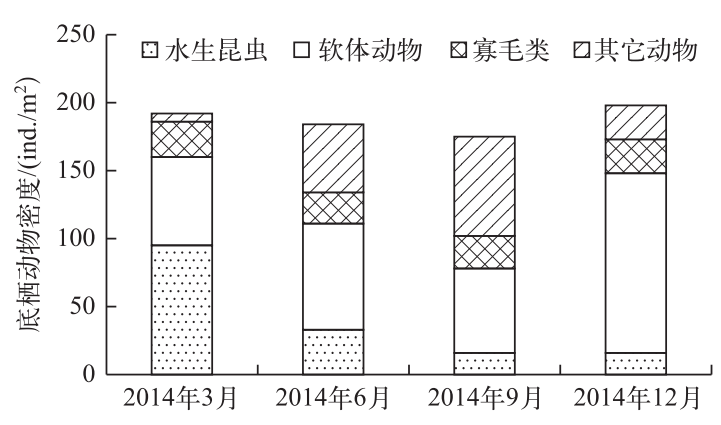

图 22014 年洞庭湖底栖动物密度组成的季节变化

Fig.2 Temporal patterns of the density macrozoobenthos of Lake Dongting in 2014

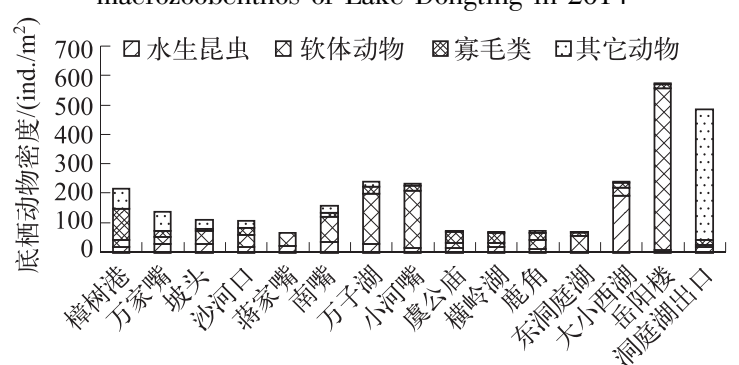

图 32014 年洞庭湖各样点 底栖动物主要类群空间分布格局

Fig.3 Spatial patterns of the main group of macrozoobenthos of each sampling site in Lake Dongting in 2014
从时间分布来看, 12 月和 3 月底栖动物密度较 高, 分别为 198 和 192 ind. $/ \mathrm{m}^{2}, 6$ 月和 9 月较低, 分 别为 184 和 175 ind. $/ \mathrm{m}^{2} .3$ 月以水生昆虫居多, 其它 月份均以软体动物居多(图 2). 从空间分布来看, 岳阳楼和洞庭湖出口底栖动物密度较高, 分别为 572 和 $482 \mathrm{ind} . / \mathrm{m}^{2}$, 岳阳楼以软体动物河蚬为主, 洞 庭湖出口以甲壳动物钩虾为主; 蒋家嘴、虞公庙和 东洞庭湖较少, 分别为 $62 、 69$ 和 $68 \mathrm{ind} . / \mathrm{m}^{2}$, 各样点 底栖动物主要类群空间分布格局见图 3.

\section{3 底栖动物群落分布与环境因子的关系}

选取底栖动物的优势种用于 CCA 分析, 图 4 反映底栖动物优势种与 2 种关键环境因子 (水温 和溶解氧浓度) 间的关系. 环境因子第 $1 、 2$ 轴间 的相关关系数为 0 , 表明分析结果可信. 除 $\mathrm{COD}_{\mathrm{Mn}}$ 和 Chl. a 浓度外共有 10 项环境因子进人 CCA 模 型, 它们共解释了 $77.1 \%$ 的群落结构变化, 其中重 要的并且有显著作用的环境因子为水温和溶解氧 $(P<0.05)$, 它们解释的群落结构变化占所有环境 因子解释的 $27.4 \%$. CCA 排序图较好地解释了大 型底栖动物与环境因子的相关关系, 所有排序轴 的检验均有显著差异 $(P<0.05), \mathrm{CCA}$ 第 1 排序轴 和第 2 排序轴的特征值分别为 0.694 和 0.583 , 共 解释了 $32.9 \%$ 的群落结构变化 (表 2 , 图 4). 
表 2 底栖动物群落分布与环境因子之间关系的 CCA 分析结果

Tab. 2 Summary statistics for the canonical correspondences analysis relating macrozoobenthos communities to environmental variables

\begin{tabular}{|c|c|c|c|c|c|c|}
\hline \multirow{2}{*}{ 环境因子 } & \multicolumn{2}{|c|}{ 变量前选 } & \multicolumn{2}{|c|}{ 与排序轴的相关系数 } & \multicolumn{2}{|c|}{ 典范系数 } \\
\hline & $P$ & $F$-ratio & 轴 1 & 轴 2 & 轴 1 & 轴 2 \\
\hline 水温 & 0.038 & 3. 4 & 0.927 & 0.231 & $0.413^{*}$ & 0.267 \\
\hline 溶解氧 & 0.048 & 2. 8 & -0.894 & 0.257 & $-0.355^{*}$ & 0.324 \\
\hline
\end{tabular}

* 表示 $P<0.05$.

第 1 轴与溶解氧浓度呈显著负相关, 与水温 呈显著正相关. 出现在第 1 轴正轴的优势种主 要有指突隐摇蚊和钩虾, 这些物种主要分布在水 温较高、流速较快的人湖口河流和洞庭湖出口 处. 出现在第 1 轴负轴的优势种主要有铜锈环棱 螺和河蚬, 它们主要分布在溶解氧浓度较高、流 速较慢的南洞庭湖 .

\section{4 水质评价}

洞庭湖综合营养状态指数显示, 蒋家嘴、东 洞庭湖和大小西湖 3 个断面呈现轻度富营养化, 其余断面为中营养水平, 全湖平均综合营养状态 指数为 48.2 , 为中营养水平. 底栖动物 ShannonWiener 平均指数与 $B I$ 指数分别为 1.30 和 5.67 ,

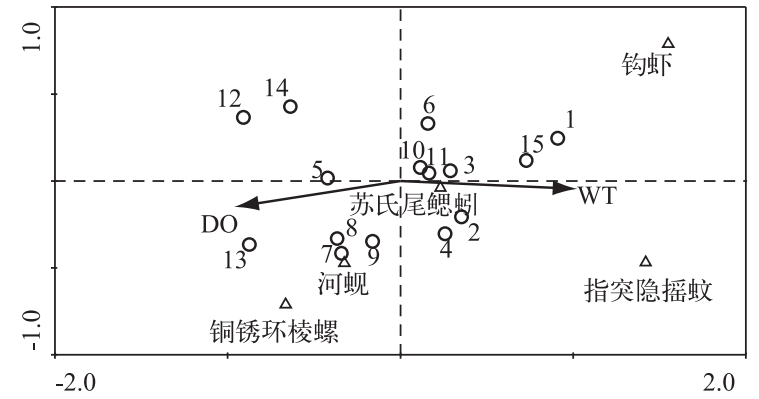

图 4 洞庭湖底栖动物群落分布与关键环境 变量的 CCA 排序图 (数字 1 15 表示采样点 $1^{\#} \sim 15^{\#}$ )

Fig.4 CCA ordination plots of macrozoobenthos communities and significant environmental variables in Lake Dongting 评价结果分别为轻污染和良好. Shannon-Wiener 指数与 $B I$ 指数评价水质的结果显示出一定的差异:万子湖、虞公庙、鹿角 3 个样点评价结果一致,但樟树港、 万家嘴、坡头、沙河口、蒋家嘴、南嘴、岳阳楼 7 个样点 Shannon-Wiener 指数评价为轻污染, 而 $B I$ 指数评价为 优; 小河嘴和大小西湖 Shannon-Wiener 指数评价为轻污染, 而 $B I$ 指数评价为良好; 横岭湖和东洞庭湖 Shannon-Wiener 指数评价为中污染, 但 $B I$ 指数评价为轻污染; 洞庭湖出口 Shannon-Wiener 指数评价为中污 染, 但 $B I$ 指数评价为优 (图 5). 可以看出, Shannon-Wiener 指数对洞庭湖水质污染的评价结果较重, 而 $B I$ 指 数评价结果较轻.
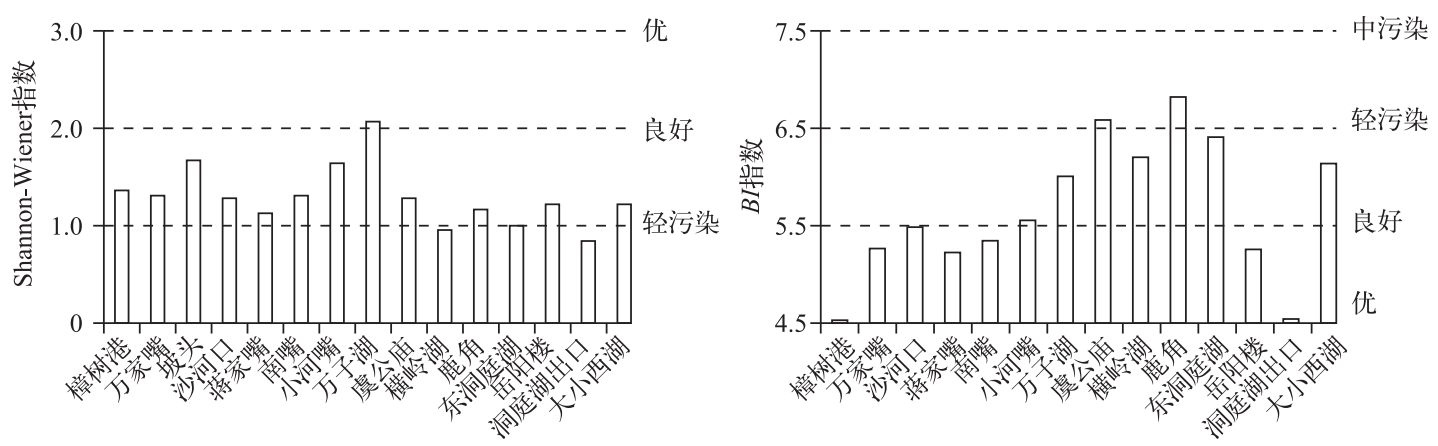

图 5 洞庭湖大型底栖动物 Shannon-Wiener 多样性指数和 $B I$ 指数水质评价

Fig.5 Water quality bioassement of Shannon-Wiener diversity index and BI of macrozoobenthos in Lake Dongting 


\section{3 讨论}

富营养化影响底栖动物群落结构, 洞庭湖在局部湖区, 如东洞庭湖和大小西湖呈轻度富营养化, 在本研究 中, 富营养化的一个重要衡量指标——综合营养状态指数与底栖动物物种数呈显著负相关 $(r=-0.64, P=$ $0.02, n=15)$. 大型通江湖泊洞庭湖底栖动物的优势种为软体动物, 洞庭湖的软体动物资源曾经十分丰 富 ${ }^{[30]}$, 但近年来有下降的趋势. $1960 \mathrm{~s}$, 洞庭湖的双壳类有 47 种, 其中 35 种为我国特有种, 优势种以大型种 类为主, 如楔蚌属 (Cuneopsis sp.)、矛蚌属 (Lanceolaria sp.) 和丽蚌属 (Lamprotula sp.) 等物种 ${ }^{[17]}$; $1995-1998$ 年调查发现, 洞庭湖的双壳类有 45 种, 其中 32 种为我国特有种 ${ }^{[31]} ; 2003-2005$ 年调查发现, 洞庭湖的双壳 类有 35 种,其中 24 种为我国特有种 ${ }^{[32]}$. 2014 年调查发现, 洞庭湖的双壳类有 11 种,其中 7 种为我国特有 种, 与 $1960 \mathrm{~s}$ 相比, 双壳类物种损失率高达 76. 6\%, 特有种损失率更高达 $80 \%$, 优势种以小型种类河蚬为主, 洞庭湖的双壳类优势种由大型的蚌类演变为小型的河蚬 . 根据 1989-1992 年对洞庭湖的调查, 洞庭湖共有 腹足类 27 种 ${ }^{[18]}$, 之后在 $1995-1998$ 年有所增加 $(30 \text { 种 })^{[31]}$, 在 $2003-2005$ 年又有所减少 $(22 \text { 种 })^{[32]}, 2014$ 年进一步减少到 17 种, 与 $1989-1992$ 年相比, 腹足类物种损失率高达 $37 \%$, 铜锈环棱螺是优势种, 在全湖广 泛分布. 洞庭湖特有种较多, 据调查, 洞庭湖软体动物种类数为 148 种, 其中特有种类数为 96 种, 占总数的 $64.9 \%$, 河螺属是我国特有属, 仅分布在长江中下游流域, 特别是洞庭湖水系 ${ }^{[33]}$, 洞庭湖蚌科 (Unionidae) 特 有种比例最高, 分布最为集中, 洞庭湖水域辽阔, 不仅为淡水双壳类免遭第四纪冰川的袭击提供了良好的避 难所, 良好的自然环境有利于特有种的形成和保存 ${ }^{[34]}$. 然而, 由于江湖阻隔、过度捕捞和水体污染等人为干 扰, 洞庭湖软体动物多样性受到严重威胁, 濒危物种较多, 腹足类濒危的物种如卵河螺 (Rivularia ovum) 、球 河螺 (R.globosa)、双龙骨河螺 (R. bicarinata)、耳河螺 (R. auriculata) 和格式短沟蜷 (Semisulcospira gredleri). 在 2014 年的调查中只发现了 1 种 (耳河螺), 而且只在南洞庭湖中的万子湖中采集到; 双壳类濒危物种均为 蚌科的种类 ${ }^{[32]}$, 如尖脊蚌 (Acuticosta sp.)、裂脊蚌 (Schistodesmus sp.)、丽蚌 (Lamprotula sp.) 、无齿蚌 (Anodonta sp.)、扭蚌 (Arconaia sp.)、楔蚌 (Cuneopsis sp.) 和矛蚌 (Lanceolaria sp.) 等,然而本文在 2014 年的调 查中只发现尖脊蚌、裂脊蚌、丽蚌和无齿蚌属的种类, 曾经在洞庭湖存在的濒危特有种一一橄榄蛏蚌 (Solenia oleivora) 和高顶鳞皮蚌 (Lepidodesma languilati) 在调查中未发现. 历史资料中有定量和定性调查的 结果, 采样点位从沿岸带到敞水带均有覆盖, 能采集到更多的种类, 而本文 2014 年 4 次定量调查研究中, 多 分布在敞水区域, 而且没有采取定性调查, 因此调查所得的软体动物种类和数量较少. 但是整体来看, 洞庭 湖软体动物资源衰退较为严重, 珍稀濒危物种较多.

表 3 不同年份洞庭湖软体动物物种数调查结果

Tab. 3 Survey results of mollusk species in different years of Lake Dongting

\begin{tabular}{lccc}
\hline 调查时间 & 双壳类(特有种) & 腹足类(特有种) & 参考文献 \\
\hline $1956-1963$ 年 & $47(35)$ & - & 文献 $[17]$ \\
$1989-1992$ 年 & - & $27(10)$ & 文献 $[18]$ \\
$1995-1998$ 年 & $45(32)$ & $30(22)$ & 文献 $[31]$ \\
$2003-2005$ 年 & $35(24)$ & $22(13)$ & 文献 $[32]$ \\
2014 年 & $11(5)$ & $17(6)$ & 本研究 \\
\hline
\end{tabular}

洞庭湖水生昆虫的种类数仅次于软体动 物, 据戴友芝等对洞庭湖底栖动物的调查结 果显示, 洞庭湖水生昆虫种类比例达到 $46.6 \%^{[12]}$; 汪星等在 2010 年对洞庭湖底栖动 物的调查结果显示, 洞庭湖水生昆虫种类比 例减少到 $35 \%^{[13]}$; 而本次调查发现洞庭湖水 生昆虫种类比例进一步下降到 $32.8 \%$. 分析 发现,洞庭湖减少的种类主要是敏感种,如毛 翅目的种类, 如戴友芝等发现洞庭湖毛翅目 种类有 5 种 ${ }^{[12]}$, 而 2014 年调查只发现 1 种纹 石蛾 (石蛾只发现了 1 种湖毛翅目种类)。此

外,洞庭湖较为常见的敏感种类蜉蝣的出现频率已不到 $50 \%$. 洞庭湖塞毛类种类数较少, 密度也较低, 优势 种为苏氏尾鳃蚓, 而在富营养化的湖泊滇池中寡毛类种类为优势种, 而且其密度也很高, 优势种为霍甫水 丝蚂 ${ }^{[6]}$.

本研究的 CCA 分析显示了水温和溶解氧浓度在影响洞庭湖底栖动物分布中的重要性, 而且二者呈显著 负相关 $(r=-0.81, P<0.01, n=15)$. 任何生物都生活在一定的温度范围内, 水温对底栖动物生长发育的影 响较早为研究者所关注, 一般认为在一定的范围内, 温度的升高将加速动物的生长发育, 缩短底栖动物的寿 
命, 提高生物生产力 ${ }^{[35-36]}$. 大型无脊椎动物的生长、繁殖等一切生命活动在很大程度上均受到温度的制 约 ${ }^{[37]}$. 本研究中, 洞庭湖优势种钩虾和指突隐摇蚊主要分布在水温较高的河流人湖口和洞庭湖出口处, 这 些种类发育较快, 个体较小, 繁殖力较强和世代周期短, 最适生态位所需的水温较高, 方差分析表明樟树港、 万家嘴、坡头、沙河口和洞庭湖出口处水温显著高于湖区其它样点, 而软体动物发育较慢, 个体较大, 繁殖力 较弱和世代周期长, 最适生态位所需的水温相对来说较低, 本文中洞庭湖优势种类软体动物如河蚬和铜锈 环棱螺主要分布在水温较低的南洞庭湖中, 可见水温是影响洞庭湖底栖动物的关键因子. 有关水体溶解氧 浓度与底栖动物关系的研究报道较多 ${ }^{[13,38-40]}$, 汪星等发现溶解氧浓度是影响洞庭湖底栖动物分布的重要环 境因子之一 ${ }^{[13]}$, 本研究同样印证了这一观点. 充足的溶解氧对底栖动物的生长发育意义重大, 尤其是在夜 晚当光合作用基本停止,而生产者和消费者仍旧消耗氧气的时候, 这种情况下底栖动物生长发育将受到很 大的影响, 因此溶解氧是影响底栖动物群落分布的关键环境因子. CCA 分析表明洞庭湖优势种如河蚬和铜 锈环棱螺等软体动物对溶解氧要求较高, 它们主要分布在溶解氧浓度较高的南洞庭湖中. 本研究同时发 现, 从空间分布来看, 洞庭湖软体动物的种类和数量呈现由南向北逐渐减少的趋势, 南洞庭湖的种类和数量 显著高于西洞庭湖和东洞庭湖,这可能与南洞庭湖较高的溶解氧浓度有关.

Shannon-Wiener 指数对洞庭湖水质污染的评价结果较重, 而 $B I$ 指数评价结果较轻, 结合综合营养状态 指数, $B I$ 生物指数的评价结果更适合洞庭湖水质生物学评价. Shannon-Wiener 多样性指数仅仅反映生物群 落的种类数而不能反映群落的物种组成之间的差异, 对种类的变化也不灵敏, 因此评价的准确度不高. $B I$ 生 物指数是目前国际上最常用的与底栖动物耐污值有关的水质生物评价指数, 它既考虑各物种本身的耐污能 力, 又考虑种类数, 能更准确地判断水质受污染程度 ${ }^{[33-34]}$. 本研究中 Shannon-Wiener 生物指数评价高估了洞 庭湖出口等 9 个样点的水质污染, 原因在于 Shannon-Wiener 多样性指数没有考虑到底栖动物种类之间的差 异, 如洞庭湖出口的优势种钩虾属于而污值相对较低的种类, 而 $B I$ 指数则考虑到了这一点, 从而较好地揭 示了洞庭湖的水质状况. 戴友芝等用底栖动物对洞庭湖整体水质进行评价, 结果显示洞庭湖整体水质良 好, 属于轻污染状态 ${ }^{[12]}$; 申锐莉等对洞庭湖的水质评价结果显示, 洞庭湖大部分水体水质主要处于轻污染状 态 ${ }^{[3]}$; 钟振宇等使用综合营养指数对洞庭湖水质进行评价, 结果表明, 洞庭湖水质处于中营养和轻度富营养 水平 ${ }^{[42]}$. 这些研究结果都与本文的评价结果较为相似, 可见用底栖动物评价洞庭湖水体状况较为可靠.

从 2014 年调查状况来看, 洞庭湖整体水质处于良好状况, 营养等级为中营养水平, 但洞庭湖流域人口 众多, 因而易受人为活动的干扰, 具有较高的生态脆弱性, 而且有很多特有和濒危的软体动物, 所以对其保 护更为重要,否则生态的典型性、多样性将易遭到破坏, 栖息的特有或稀有种则面临生死存亡之秋.

\section{4 参考文献}

[ 1 ] 黄代中, 万 群, 李利强等. 洞庭湖近 20 年水质与富营养化状态变化. 环境科学研究, 2013, 26(1) : 27-33.

[2] 龚志军, 谢 平, 唐汇娟等. 水体富营养化对大型底栖动物群落结构及多样性的影响. 水生生物学报, 2001,25 (3) : 210-216.

[ 3 ] 申锐莉, 张建新, 鲍征宇等. 洞庭湖水质评价: 2002-2004 年. 湖泊科学, 2006, 18 (3): 243-249. DOI 10. 18307/2006. 0308.

[ 4 ] 陈其羽, 梁彦龄, 吴天惠. 武汉东湖底栖动物群落结构和动态的研究. 水生生物学集刊, 1980, 7: 41-56.

[ 5] 龚志军. 长江中游浅水湖泊大型底栖动物的生态学研究 [学位论文]. 武汉: 中国科学院水生生物研究所, 2002.

[ 6 ] 王丑明, 谢志才, 宋立荣等. 滇池大型无脊椎动物的群落演变与成因分析. 动物学研究, 2011, 32(2) : 212-221.

[ 7 ] Wallace JB, Webster JR. The role of macroinvertebrate in stream ecosystem function. Annual Review of Entomology, 1996, 41: 115-139.

[ 8 ] Waters TF. Dynamics in stream ecology. Canadian Journal of Fisheries and Aquatic Sciences, 1993, 118: 1-8.

[ 9 ] Peterson BJ, Deegan L, Helfrich J et al. Biological responses of a tundra river to fertilization. Ecology, 1993, 746: 53-72.

[10] Morse JC, Bae YJ, Munkhjargal G et al. Freshwater biomonitoring with macroinvertebrates in East Asia. Frontiers in Ecology and the Environment, 2007, 5: 33-42.

[11] Ricciardi A, Rasmussen JB. Extinction rates of North American water fauna. Conservation Biology, 1999, 13: $1220-1222$.

[12] 戴友芝, 唐受印, 张建波. 洞庭湖底栖动物种类分布及水质生物学评价. 生态学报, 2000, 20(2): 277-282.

[13] 汪 星, 郑丙辉, 刘录三等. 洞庭湖典型断面底栖动物组成及其与环境因子的相关分析. 中国环境科学, 2012, 
32(12) : 2237-2244.

[14] 汪 星, 郑丙辉, 李 黎等. 基于底栖动物完整性指数的洞庭湖典型断面的水质评价. 农业环境科学学报, $2012, \mathbf{3 1}(9)$ : 1799-1807.

[15] 江 辉, 肖克宇, 余建波等. 沅江南洞庭湖软体动物资源初步调查. 湖南农业大学学报: 自然科学版, 2007, 33 (2) : 205-207.

[16] 谢志才, 张君倩, 陈 静等. 东洞庭湖保护区大型底栖动物空间分布格局及水质评价. 湖泊科学, 2007, 19(3): 289-298. DOI 10. 18307/2007. 0310.

[17] 张 坌, 李世成, 刘月英. 洞庭湖及其周围水域的双壳类软体动物. 动物学报, 1965, 17(2): 197-211.

[18] 胡自强. 洞庭湖及其周围主要水域的螺类. 湖南师范大学: 自然科学学报, 1993, 16(1): 80-85.

[19] Epler JH. Identification manual for the Larval Chironomidae of north and south Carolina. Raleigh : North Carolina Department of Environment and Natural Resources Division of Water Quality, 2001.

[20] Brinkhurst RO. Guide to the freshwater aquatic Microdrile Oligochaetes of North America. Ottawa: Department of Fisheries and Oceans, 1986.

[21] 刘月英, 张文珍, 王跃先等. 中国经济动物志: 淡水软体动物. 北京: 科学出版社, 1979.

[22] Morse JC, Yang LF, Tian LX. Aquatic insects of china useful for monitoring water quality. Nanjing: Hohai University Press, 1994.

[23] 国家环境保护总局《水和废水监测分析方法》编委会. 水和废水监测分析方法. 北京: 中国环境科学出版 社, 2002.

[24] 中国环境监测总站. 湖泊 (水库) 富营养化评价方法及分级技术规定. 北京: 科学出版社, 2001.

[25] Ter Braak CJF, Verdonschot PFM. Canonical correspondence analysis and related multivariate methods in aquatic ecology. Aquatic Sciences, 1995, 57: 255-289.

[26] Ter Braak CJF, Šmilauer P. CANOCO reference manual and CanoDraw for Windows user's guide: software for canonical community ordination (version 4.5). New York: Microcomputer Power Ithaca, 2002.

[27] 王建国, 黄恢柏, 杨明旭等. 庐山地区底栖大型无脊椎动物耐污值与水质生物学评价. 应用与环境生物学报, $2003, \mathbf{9}(3): 279-284$.

[28］王备新, 杨莲芳. 我国东部底栖无脊椎动物主要分类单元耐污值. 生态学报, 2004, 24(12): 2768-2775.

[29] Qin CY, Zhou J, Cao Y et al. Quantitative tolerance values for common stream benthic macroinvertebrates in the Yangtze River Delta, Eastern China. Environmental Monitoring and Assessment, 2014, 186: 5883-5895.

[30］舒凤月, 王海军, 崔永德等. 长江流域淡水软体动物物种多样性及其分布格局. 水生生物学报, 2014, 38(1): 19-26.

[31] 吴小平, 梁彦龄, 王洪铸等. 长江中下游湖泊淡水贝类的分布及物种多样性. 湖泊科学, 2000, 12(2)：111118. DOI 10. 18307/2000. 0203.

[32] 舒凤月, 王海军, 潘保柱等. 长江中下游湖泊贝类物种濒危状况评估. 水生生物学报, 2009, 33(6) : 1051-1058.

[33] 舒凤月. 沼肺螺类的解剖学分类特征及中国淡水贝类的多样性格局 [学位论文]. 武汉: 中国科学院水生生物研 究所, 2009 .

[34] 胡自强. 中国淡水双壳类特有种的地理分布. 动物学杂志, 2005, 40(6):80-83.

[35] Humpesch UH. Life cycle and growth fates of Baetis spp. (Ephemeroptera: Baetidae) in the laboratory and in two stone streams in Austria. Freshwater Ecology, 1979, 9: 467-479.

[36] Tokeshi M. Life cycles and population dynamics. The Chironomidae: The biology and ecology of non-biting midges. London: Chapman \& Hall, 1995: 225-268.

[37] Benke AC. Concepts and patterns of invertebrate produation in running water. Verhandlungen der Internationalen Vereinigung fuer Theoretische and Angewandte Limnologie, 1993, 25: 15-38.

[38 ] Beisel JN, Usseglio-Polatera P, Moreteau JC. The spatial heterogeneity of a river bottom : a key factor determining macroinvertebrate communities. Hydrobiologia, 2000, 422(423) : 163-171.

[39] 熊 晶, 谢志才, 张君倩等. 傀儡湖大型底栖动物群落与水质评价. 长江流域资源与环境, 2010, 19(S1): 132-137.

[40] 蒋小明, 程建丽, 熊 晶等. 黄盖湖水系河源区一一皤河大型无脊椎动物群落与水质评价. 长江流域资源与环 境, $2011,20(9)$ : 1040-1046.

[41] 童晓立, 胡慧建, 陈思源. 利用水生昆虫评价南昆山溪流的水质. 华南农业大学学报, 1995, 16(3): 6-10.

[42］钟振宇，陈 灿. 洞庭湖水质及富营养化评价. 环境科学与管理, 2011, 36(7): 169-173. 


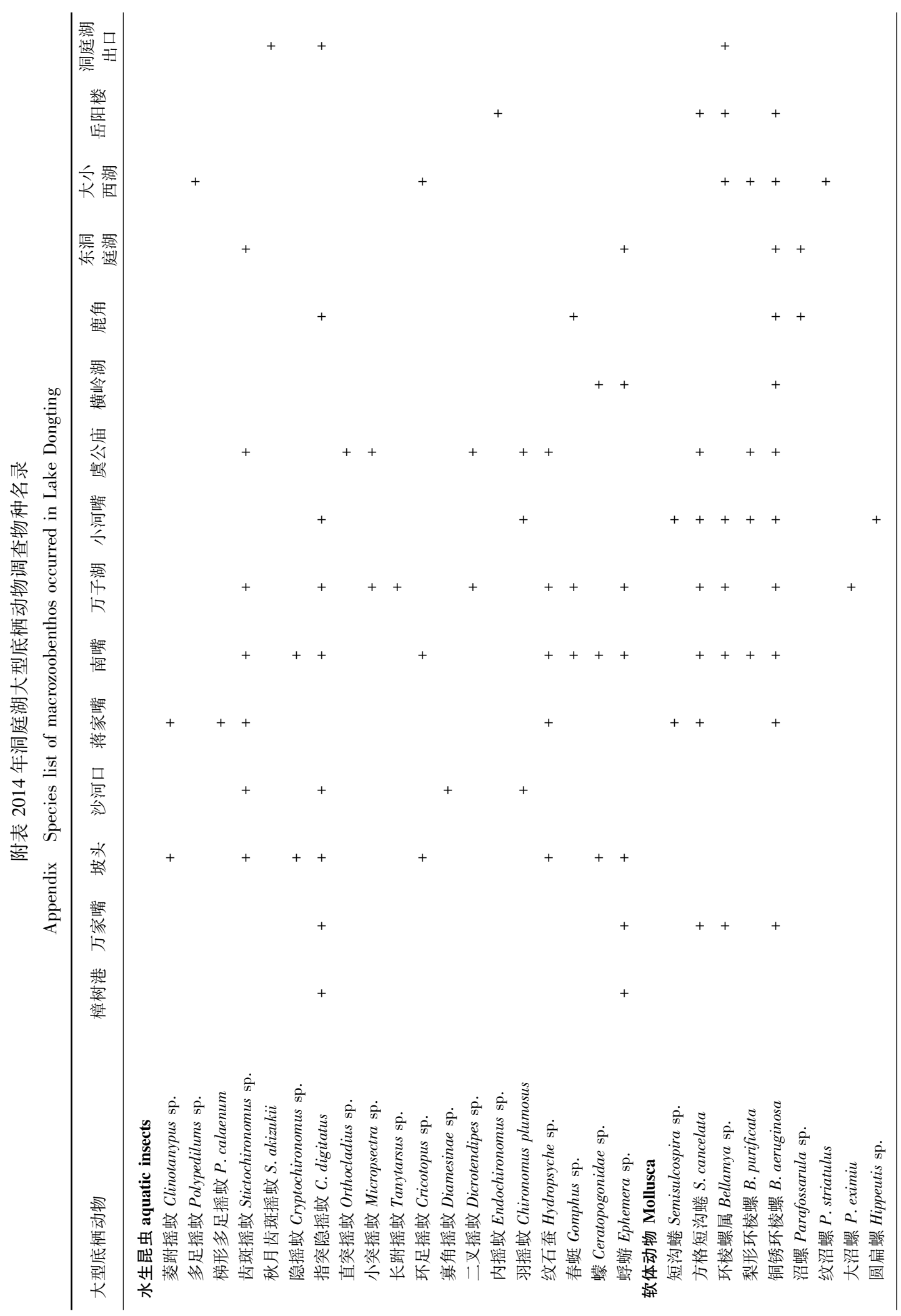




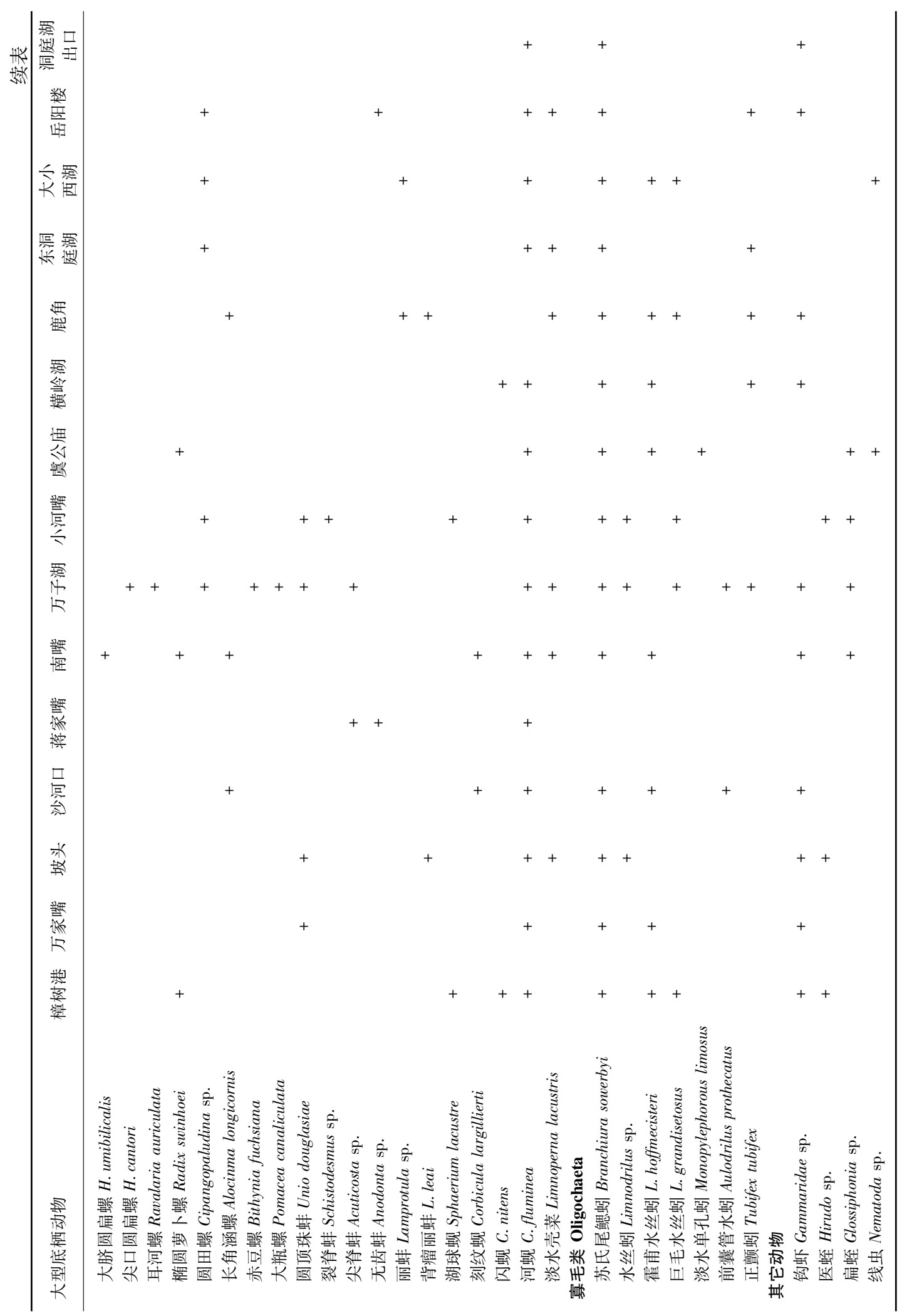

